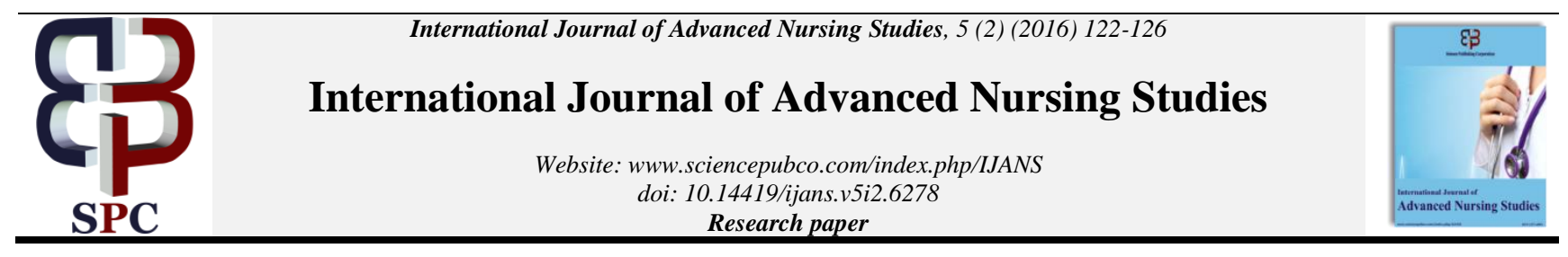

\title{
A home-based health care programme to facilitate coping in survivors of cerebro-vascular accidents and their Caregivers in Oshana Region, Namibia
}

\author{
Suama W Kuugongelwa *, Louis F Small \\ University of Namibia, Private Bag13301, Windhoek, Namibia \\ *Corresponding author E-mail: skuugongelwa@unam.na
}

\begin{abstract}
A cerebro-vascular accident entails the sudden death of brain cells resulting from a problem with the blood supply. The patient is consequently left with varying degrees of disability, and usually requires the assistance of a caregiver. This article describes the development of a home-based health care programme intended to facilitate optimal functioning, which formed the final phase of a qualitative study that explored and described the experiences of survivors of cerebrovascular accidents and their caregivers. The development of this programme was based on the four themes that emerged from the original study and which were conceptualised by applying Dickoff, James and Wiedenbach's (1968) practice theory. These four themes were restructured as four dynamics, namely, reframing knowledge and skills regarding self-care, modifying the daily routine, assisting with the adjustment to altered social relationships, and reframing negative emotions. The programme was implemented over four days and an evaluation was done after two months. The feedback revealed that the survivors and their caregivers had benefitted with regard to the skills and knowledge gained from the educational programme.
\end{abstract}

Keywords: Caregivers; Cerebro-Vascular Accidents; Facilitation; Home Care; Optimal Functioning; Survivors.

\section{Introduction}

A cerebro-vascular accident entails the sudden death of brain cells resulting from a problem with the blood supply. When the blood flow to the brain is impaired, oxygen and important nutrients cannot be delivered, resulting in abnormal brain function. Blood flow to the brain can be disrupted by either a blockage in, or a rupture of, an artery to the brain.

A cerebro-vascular accident is one of the diseases that are commonly found in Namibia, and is one of the main causes of disability and the fourth largest cause of death in that country. Since 2001, 131 out of 306 recorded cases of patients suffering from cerebro-vascular disease at the Oshakati Intermediate Hospital have died (Ministry of Health and Social Services, 2005, 2010). The incidence of cerebro-vascular accident increases with age and is consistently higher in males than in females.

The survivor of a cerebro-vascular accident and his or her caregiver are the primary active participants in managing the illness in terms of achieving recovery and preventing complications. During the first months after being discharged, the survivors and their caregivers face the re-establishment of daily routines within the context of changed physical functioning. Establishing a routine of daily activities is part of learning how to manage at home in the face of functional limitations and disabilities. According to Doolittle (2003), changes in routine include being confined to bed with a few excursions into public places, and consequently daily schedules have to be established for routine activities such as eating, bathing and resting. If routines are not re-established, survivors and caregivers experience increased turmoil and disruption during the transition period.
Caring for the survivor of a cerebro-vascular accident, brain injury or any other trauma affecting cognitive and physical ability is a big challenge for the caregiver (Smith, 2004). Life after a cerebrovascular accident depends on the degree of ability that is lost or affected by the accident, as well as on the extent of the brain damage and where in the brain the accident occurred.

In Namibia, providing care for the survivors of cerebro-vascular accidents in home settings is an increasingly common practice. Since early discharge from acute care settings is becoming the norm, survivors of cerebro-vascular accidents spend a significant portion of their recovery at home. As a result, informal caregivers, individuals with no formal health education, provide more complex care for longer periods than ever before (McCann \& Christiansen, 2004; Smit, Forster \& Young, 2004; Rodgers, Bond \& Curless, 2005). It has also been noted that caring for a person who has had a cerebro-vascular accident can have a detrimental effect on the caregiver's health leading to the health service having to respond to their needs as well (Low, Roderick \& Payne, 2004; Ritcher \& Peu, 2004). Even in the Namibian cultures, where the care of the ill is an anticipated responsibility of family members, the complexities of today's medical regimens and the burdens of the caregiver's own family or environmental milieu pose an overwhelming challenge.

In order to offer better support and understand the functional limitations and challenges associated with the survivors' disabilities, especially those from the rural areas of Namibia, it is important to identify the utilisation of the strengths both within the family and at the community level in order to facilitate optimal functioning at home. Adequate information about the survivor's condition and the care that is needed, as well as the availability of social support, material resources and financial means, can enhance both the survivors' and the caregivers' self-esteem and thus assist caregivers 
to cope with the demands of care at home. Therefore, the quality of care for the survivors of cerebro-vascular accidents from the rural areas of Namibia is not only determined by their family, but also by the many spheres of influence that can have an impact on the quality of care that caregivers provide (Kuugongelwa \& Small, 2015).

Thus the philosophy of a home-based health care emphasises the harnessing of resources and bolstering of optimism. In so doing, the survivors of cerebro-vascular accidents and their caregivers may be guided to formulate new, or to strengthen already existing, functional abilities and thereby instil an attitude which promises positive returns for the survivors. In addition to facilitating their functioning with disabilities, the survivors may also be empowered to use different coping methods and thus to reconceptualise the condition as a manageable challenge despite its restrictions (Kettunen, Oskiparta \& Liimatainen, 2001).

\section{Purpose}

This study presents a conceptualisation of a home-based health care programme comprising multicomponent interventions, which draws together all the possible determinant factors and coping methods for both caregivers and the survivors of cerebro-vascular accidents in order achieve optimal functioning at home. The implementation of this programme can result in a reduction in the burden of caregiving and improved coping with the demands of care, as well as improved coping with the condition burden in survivors (Gitlin, Belle \& Burgio, 2003).

\section{Study design and methodology}

The original study was qualitative, explorative and contextual in design. The population consisted of two groups, namely, the survivors of cerebro-vascular accidents and their respective caregivers. During the interviews conducted, four themes emerged. These themes were conceptualised on the basis of Dickoff, James and Wiedenbach's (1968) practice theory. Based on this conceptualisation, a home-based health care programme was developed, implemented and evaluated. The implementation and evaluation of the programme will be discussed in other articles.

\subsection{Ethical considerations}

As part of the original study, approval was obtained from the Ministry of Health and Social Services. The Oshana Health and Regional Council also approved the request to conduct this study. During the programme's implementation phase, informed consent was obtained and an assurance was given regarding anonymity and the possibility of withdrawing at any time.

\section{The home-based health care programme}

To alleviate the negative experiences and to facilitate coping with the demands of caring and the disabilities of the survivors of cerebro-vascular accidents, four dynamics were identified. These four dynamics address the four themes that emerged from the original study:

1) Reframe knowledge and the skills of self-care

2) Modify the daily routine

3) Adjust to altered social relationships

4) Reframe negative emotions.

\subsection{Objectives for the home-based health care pro- gramme}

The specific purpose of the envisaged home-based health care programme was to facilitate an optimal physical, social and emotional functional status for the survivors and their caregivers at home. This was done by initiating the four dynamics identified.

\subsection{Discussion of the home-based programme}

The home-based health care programme was conceptualised according to some of Dickoff et al.'s (1968) essential ingredients of a situation-producing concept; these include the goal content, which comprises the aim of the home-based health care programme and the desired situation to be brought into existence the facilitation of coping with the demands of care at home, the prescription of activities or the actions to be taken, as appropriate and therefore likely to lead to the realisation of the goal content. Activity prescription includes the notion that while much is expected of a facilitator in implementing the home-based health care programme (Glanz, Rimer \& Viswanath, Orleans 2008), it is important that the survivors and caregivers as the recipients of the empowerment programme should possess the essential characteristics that will enable them to be responsive and receptive to learning how to function optimally and to cope with the demands of their disabilities. Such characteristics include curiosity, selfawareness, responsibility, decision-making abilities, good interpersonal relationships, communication, motivation and enthusiasm. These will enable them to strive to improve their abilities despite the many aspects that influence the environment negatively (Miller, 2003).

\subsection{Initiating the four programme dynamics}

Each of the four dynamics of the programme that were identified will be described individually.

Dynamic 1: Reframing knowledge and skills relating to self-care This dynamic is focused on alleviating the experiences of inability to self-care and dependency on others for help, including bathing, dressing, transfers, immobility and disturbed sleeping patterns (McLean, Roper-Hall, Mayer \& Main, 2006; Van Excel, Scholte, Brouwer, Van der Berg, Koopmanschap \& Van den Bos, 2004; Becker, 2004; Doolittle, 2003; McLaughlin, 2002).

In not being able to carry out the activities that individuals personally initiate and perform on their own behalf in maintaining life, health and wellbeing, the survivors are dependent on others, which consequently compel them to request help.

The survivors are also at risk of experiencing sleep disorders, often being challenged by insomnia, which is caused by conscious or real concerns, such as worries about adapting to paralysis, as well as other uncertainties. These sleep disturbances may also have a harmful effect on caregivers, as they may remain wakeful during the night, anticipating that the survivors might need them. This means that caregivers are available all the time (Han \& Haley 2007; Myco, 2006). In this regard, it is essential that the caregivers receive counselling that will assist them to strike a balance between acknowledging the survivor's disability and the demands of care. It should also help them with methods for coping, to cherish each day they have with the survivor and not to be discouraged by the reality that lies ahead. Moreover, such caring which acts with minimal limitations is more likely to translate into the survivor's control over the inability to self-care, the ability to see the bright side of the situation and to not always take their situation seriously (Peu, 2008; Charmaz, 2005; Ritcher \& Peu, 2004; Leininger, 2004).

Therefore, the interventions of the home-based health care programme relating to self-care, the use of meaning-based coping techniques such as using alternative measures for improving mobility, carrying out dressing activities within limitations and promoting normal sleep patterns can mitigate the negative impacts of the inability to self-care and dependency on others, and so may facilitate coping (Lee-Hood Ahmad, Lennihan, Moore, Naylor, Tarvestad \& Zorowitz, 2009; Donnellan, Hevey, Hickey \& O'Neill, 2006). Additionally, it is important that the survivors of cerebro-vascular accidents and their caregivers in rural areas be supplied with knowledge of and training in certain skills. Such knowledge-based empowerment should include skills for accessing help from a professional or community-based resource or per- 
son/s, if needed (Lee-Hood Ahmad et al., 2009; Stajduhar, Leigh Martin, Barwish \& Fyle, 2008).

If they are able to access information pertaining to the survivors disabilities, then caregivers will be more prepared for what they may encounter during the course of care. Knowledge can therefore ease the burden of providing care, as it increases perceived control and can therefore facilitate the caregivers' adaptation to the demands of care (Stajduhar et al., 2008).

Dynamic 2: Modifying the daily routine

This dynamic is focused on mitigating the experiences of inability when attempting to function as a marital partner, parent and financial supporter. Cerebro-vascular accidents contribute directly to changes in family relationships, which often result in feelings of powerlessness. Role reversal commonly occurs, with the spouse and children taking on many of the survivors' previous roles and tasks. At the same time, survivors feel useless because they cannot perform their original roles and have to take on a more dependent role within the family (Wellwood, Dennis \& Warlow, 2007).

Additionally, the survivors and their caregivers experience financial challenges in meeting daily household demands, since the survivor's income has either reduced or disappeared altogether (Reinardy, Kane, Huck, Thiede Call \& Shen, 2007; Mui, 2006; Parks \& Pilisuk, 2005). In this regard, it is essential that the caregivers receive counselling to help them adapt and change their roles and expectations so that they can assume the responsibilities that once belonged to the disabled member. Moreover, the shifting and sharing of responsibilities enables necessary family processes to continue (Cookfair, 2004).

To actualise this dynamic, it is important for these survivors and their caregivers to obtain some form of assistance to alleviate the financial burden so that they can cope with the demands of care at home. Although facilitating the provision of financial assistance to the caregivers is not within the decision-making domain of the individual health care provider, a recommendation can be made for the survivors of cerebro-vascular accidents to receive a social welfare grant from the Namibian government to assist them in providing for their needs.

Dynamic 3: Adjusting to altered social relationships

Here the focus is on alleviating the experiences of disrupted social interaction, since survivors are unable to fulfil their previous social roles; in addition, the family and friends may not provide the social support needed (Boswell \& Wingrove, 2009; Peu, 2008; Kim \& Keshian, 2007; Trochim, 2006). In this respect, the survivors and their caregivers need supportive information to be able to develop meaningful social relationships that provide satisfaction and assistance when needed (Lee-Hood Ahmad et al., 2009; Hartz \& Splain, 2005; McEwen, 2004; Stanhope \& Lancaster, 2000).

Therefore, the interventions of the home-based health care programme relate to enhancing social interaction, employing social integration such as re-entry into the community, and restoring the socialising skills and leisure activities that can lead to social opportunities. This may include access to community centres, church groups and other organisations which offer recreation programmes that can mitigate the effects of negative social disruption (LeeHood Ahmad et al., 2009).

In addition, productive social relations, social support and social functioning can facilitate integration into the community and close personal relationships with others. This is a pathway for caregivers' access to resources that facilitate coping with the demands of caring for the survivors concerned (Harway, 2006). To that end, and within their cultural context, the caregivers should further make use of their confidant, community-based support groups, which can provide them with social support. Other potential caregivers outside the family circle whose support the caregivers can make use of are friends who can be relied on for short-term minor care, and social workers who can facilitate counselling and referential support (Mitchell, 2011).

It can therefore be concluded that in order to adjust to the altered social relationships that the survivors of cerebro-vascular accidents and their caregivers experience, balanced coping should be strengthened through the use of the resources available at the family and the community level (Smit et al., 2004).

Dynamic 4: Reframing negative emotions

This dynamic focuses on supportive educative guidance for the survivors of cerebro-vascular accidents and their caregivers to help them explore the knowledge and skills that will enable them to deal with anger, worry and guilt (Lee-Hood Ahmad et al., 2009; Gallozi, 2008; McMurdo, 2003; Gibson, Swartz \& Sandenberg, 2002).

The negative emotional experiences of both survivors and caregivers encompass all the verbal or physical manifestations of the upset relating to disabilities, maladaptive responses to changes and the demands for caring, which all require counteraction to restore balance. In this regard, it is essential that the survivors and their caregivers receive counselling in order for them to strike a balance between accepting the disabilities and the demands for care, and to use methods of coping, cherish each day they have together and not to be discouraged by the restricted lifestyle that lies ahead.

In addition, caregivers should be well informed so that should a survivor of cerebro-vascular accident become upset and take out his/her anger on others, they are able to devise a firm plan and adopt an understanding manner that will help the survivor react and deal more effectively with the anger. This may include participating in activities that make them feel better, such as mild exercise, or attending a religious, social or community event. Sharing their experiences with others is also recommended as an effective way to reduce feelings of isolation, withdrawal and helplessness. In conclusion, setting realistic goals and priorities, and working through their feelings together should be explained to survivors and caregivers as being meaning-based coping techniques that enhance self-esteem, facilitate coping and mitigate the impacts of negative emotional experiences (McLeod, 2007; Senelick, Rossi, \& Dougherty, 2005; Marzo, 2009).

This conceptual framework for a home-based health care programme explains a complementary relationship between problem management and emotional coping. In return, a healthy emotional status in the caregiver has a positive influence on survivors' perceptions of coping with the burden of disabilities. Furthermore, the ability to manage the problems enables caregivers to provide quality care that, in turn, facilitates optimal functioning in survivors.

\section{Results}

Activities aimed at facilitating self-care focused coping methods can enhance the reframing of knowledge and skills related to selfcare in survivors and their caregivers. Similarly, activities aimed at the facilitation of altered role function and performance-focused coping enables both survivors and caregivers to modify the daily routine, adjust to altered social relationships and alleviate negative emotions. This can result in the survivors of cerebro-vascular accidents and their caregivers being able to function optimally at home.

\section{Conclusions}

Effective mitigation of negative experiences and the facilitation of coping with the demands of care for the caregivers of survivors of cerebro-vascular accidents require the implementation of a homebased health care programme comprising multi-component interventions, which draws together all the possible determinant factors and the coping methods of the survivors and their caregivers, in order for them to implement self-care goal-directed activities to facilitate optimal functioning at home. As a function of the implementation of the interventions of the envisaged home-based health care programme, four main coping outcomes, namely, the knowledge and skills of self-care for both survivors and caregivers and the modification of the daily routine, adjustment to altered social relationships by survivors and caregivers as the recipients of the programme interventions, and the realisation of survivors' 
emotional well-being as the beneficiaries of their caregiver's coping efforts, would be attained (Donnellan et al., 2006).

\subsection{Limitations}

The original programme formed part of a study that was conducted in Oshiwambo and then translated into English. This could have resulted in certain of the meanings being lost in translation.

\subsection{Recommendations}

An evaluation of the support programme implementation found that this programme could be implemented in hospitals and could also be considered for inclusion in the curriculum content for prospective nurses at the local training institutions.

\section{Acknowledgement}

This study was conducted with the permission of the Ethical and Research Committee of the Namibian Ministry of Health and Social Services, the University of Namibia, Faculty of Health Sciences, School of Nursing and Public Health, and the Oshana Regional Health Director. These parties are gratefully acknowledged for their contributions towards the completion of the study. Special thanks are extended to all the survivors of cerebro-vascular accidents and their caregivers who participated in this study for making themselves available, sharing their experiences and participating in the interventions.

\section{References}

[1] Becker, G. (2004). Continuity after a stroke: Implications for lifecourse disruptions in old age. Gerontologist, 33, 148-158, Berkeley: University of California Press. http://dx.doi.org/10.1093/geront/33.2.148.

[2] Boswell, D., \& Wingrove, J. M. (2009). The handicapped person in the community: A reader and source book. Retrieved September 29, 2009 from http://books.google.com.na/books?id $=$ MEQOAAAAQAAJ \& pg = PA..

[3] Charmaz, K. (2005). Loss of self: A fundamental for suffering in the chronically ill. Sociology of Health and Illness, 5, 168-195. http://dx.doi.org/10.1111/1467-9566.ep10491512.

[4] Cookfair, J. M. (2004). Nursing care in the community (2nd ed.). St Louis, MO: Mosby.

[5] Dickoff, J., James, P., \& Wiedenbach, E. (1968). Theory in a practice discipline: Part 1. Practice oriented theory. American Journal of Nursing Company. Nursing Research, 17(5), SeptemberOctober, 17(5), 415-444. http://dx.doi.org/10.1097/00006199196809000-00006.

[6] Donnellan, C., Hevey, D., Hickey, A., \& O’Neill, K. (2006). Defining and quantifying coping strategies after stroke: A review. Jour nal of Neurology, Neurosurgery, and Psychiatry, 77, 1208-1218. http://dx.doi.org/10.1136/jnnp.2005.085670.

[7] Doolittle, N. D. (2003). The experience of recovery following lacunar stroke. Rehabilitation Nursing, 17(3), 122-125. http://dx.doi.org/10.1002/j.2048-7940.1992.tb01528.x.

[8] Gallozi, C. (2008). Coping with guilt. Retrieved from http://www.personal-development.com/chuck/guilt.htm

[9] Gibson, K., Swartz, L., \& Sandenberg.R. (2002). Counseling and coping. Cape Town: Oxford University Press.

[10] Gitlin, L., Belle, S., Burgio, L., et al. (2003). Effects of multicomponent interventions on caregiver burden and depression: The REACH multisite initiative at 6-month follow up. Psychology of Aging. 8(3), 361-374. Retrieved from http://dx.doi.org/1037/08827974.18.3.361.

[11] Glanz, K., Rimer, B. K., Viswanath, K. \& Orleans C .T. (4 ${ }^{\text {th }}$ Eds) (2008). Health behavior and health education: Theory, research, and practice (4th ed.). California: Jossey Bass.

[12] Han, B., \& Haley, W. E. (2007). Family caregiving for patients with stroke. Review and Analysis: Stroke, 30(7), 1478-1485.

[13] Hartz, G. W., \& Splain, D. M. (2005). Psychosocial intervention in long-term care: An advanced guide. London: Haworth Press.

[14] Harway, M. (2006). Treating the changing family: Handling normative and unusual events. Canada: John Wiley.
[15] Kettunen, T., Oskiparta, M., \& Liimatainen, L. (2011). Empowering counselling - a case study: Nurse-patient encounter in a hospital. Health Education Research, 16(2), 227-238. Retrieved from http://dx.doi.org/10.1093/her/16.2.227.

[16] Kim, J. J., \& Keshian, J. C. (2007). Old caregivers: A growing challenge for community health nurse. Journal of Community Health Nursing, 11 , 63-70. http://dx.doi.org/10.1207/s15327655jchn1102 1.

[17] Kuugongelwa, S., \& Small, L. (2015). Assessment of experiences of survivors of cerbro-vascular accidents and their caregivers functioning at home in the Oshana region of Namibia. International Journal of Advanced Nursing Studies, 4(2), 153-157. http://dx.doi.org/10.14419/ijans.v4i2.5164.

[18] Lee-Hood Ahmad, E., Lennihan, L., Moore, S., Naylor, D., Tarvestad, D., \& Zorowitz, R. (2009). HOPE: The stroke recovery guide. USA: National Stroke Association.

[19] Leininger, M. M. (2004). Caring: An essential human need. Proceedings of the Three National Caring Conferences. Wayne State University Press, Detroit, Michigan 48202.

[20] Low, J. T. S., Roderick, P., \& Payne, S. (2004). An exploring looking at the impact of domiciliary and day hospital delivery of stroke rehabilitation on informal carers. Clinical Rehabilitation, 18, 776784. http://dx.doi.org/10.1191/0269215504cr748oa.

[21] Marzo, D. (2009). Why not me? Dealing with survivor guilt in the aftermath of a disaster. Retrieved from http;//www.selfhelpmagazine.com/articles/trauma/guilt.html

[22] McCann, J. J., \& Christiansen, K. E. (2004). Home care. In A. G. Lueckenotte (Ed.), Gerontologic nursing (pp. 913-943). St. Louis, MO: Mosby.

[23] McEwen, M. (2004). Community-based nursing: An introduction. Philadelphia, PA: WB Saunders.

[24] McLaughlin, M. (2002). Recovery self-care skills guides available. Mental Health E-News, 02-49. Retrieved August 23, 2009 from http://www.namiscc.org/Recovery/ 2002/Recovery Guides.htm

[25] McLean, J., Roper-Hall, A., Mayer, P., \& Main, A. (2006). Service needs of stroke survivors and their informal carers: A pilot study. Journal Advanced Nursing, 16, 559-564. http://dx.doi.org/10.1111/j.1365-2648.1991.tb01691.x.

[26] McLeod, B. W. (2007). Caregiving: The spiritual journey of love, loss and renewal. New York: John Wiley.

[27] McMurdo, M. (2003). Stroke (cerebro-vascular accident). Retrieved September $12, \quad 2009$ from http://www.netdoctor.co.uk/diseases/facts/stroke.htm

[28] Miller, J. F. (2003). Coping with chronic illness: Overcoming powerlessness (2nd ed.). Philadelphia, PA: FA Davis.

[29] Ministry of Health \& Social Services. (2005). Information system (2001-2005). Oshakati District, Republic of Namibia: HIS Office.

[30] Ministry of Health \& Social Services. (April 2009-February 2010). Information System. Oshakati District, Republic of Namibia: HIS Office.

[31] Mitchell, G, R. (2011). Empowering caregivers. Retrieved December 1, 2011 from www.caregivers.com

[32] Mui, A. C. (2006). Caring for frail elderly parents: A comparison of adult sons and daughters. The Gerontologist, 35, 86-95. http://dx.doi.org/10.1093/geront/35.1.86.

[33] Myco, F. (2006). Nursing care of the hemiplegic stroke patient (1st ed.). London: Harper and Row.

[34] Parks, S. H., \& Pilisuk, M. (2005). Caregiver burden: Gender and psychological costs of caregiving. American Journal of Orthopsychiatry, 61, 501-509. http://dx.doi.org/10.1037/h0079290.

[35] Peu, M. D. (2008). Home/community-based care. Pretoria: Van Schaik.

[36] Reinardy, J. R., Kane, R. A., Huck, S., Thiede Call, K., \& Shen, C. (2007). Beyond burden: Two ways of looking at care given burden. Res Aging, 21, 106-127. http://dx.doi.org/10.1177/0164027599211005.

[37] Ritcher, S., \& Peu, M. D. (2004). The educational and supportive needs of informal caregivers working at Refentse Clinic, Hammanskraal. Curationis, 27(1), 31-40.

[38] Rodgers, H., Bond, S., \& Curless, R. (2005). Inadequacies in the provision of information to stroke patients and their families. Age Ageing, 30, 129-133. http://dx.doi.org/10.1093/ageing/30.2.129.

[39] Senelick, R. C., Rossi, P. W., \& Dougherty, K. (2005). Living with stroke: A guide for families: Help and new hope for all those touched by stroke. New York: McGraw-Hill.

[40] Smit, J., Forster, A., \& Young, J. (2004). A randomized trial to evaluate an education programme for patients and carers after stroke. Clinical Rehabilitation, 18, 726-736. http://dx.doi.org/10.1191/0269215504cr790oa. 
[41] Smith, C. E. (2004). Caregiving effectiveness in families managing complex technology at home: Replication of a model. Nursing Research, 48, 120-128. http://dx.doi.org/10.1097/00006199199905000-00002.

[42] Stajduhar, K., Leigh Martin, W., Barwish, D., \& Fyle, G. (2008) Factors influencing family caregivers' ability to cope with providing end-of-life cancer care at home. Cancer Nursing 31(1), 77-85. Retrieved from http://dx.doi.org/10.1097/01.NCC.0000305686.36637.b5.

[43] Stanhope, M., \& Lancaster, L. (2000). Community health nursing: Process and practice for promoting health. Washington, DC: Mosby.

[44] Trochim, W. M. K. (2006). Social interaction. Retrieved August 23, 2009 from http//wikipedia.org/wiki/Social interaction

[45] Van Excel, N. J. A., Scholte, W. J. M., Brouwer, W. B. F., Van der Berg, B., Koopmanschap, M. A., \& Van den Bos, G. A. M. (2004). Instruments for assessing the burden of informal caregiving for stroke patients in clinical practice. Journal Clinical Rehabilitation, 18, 203-214. http://dx.doi.org/10.1191/0269215504cr723oa.

[46] Wellwood, I., Dennis, M. S., \& Warlow, C. P. (2007). Perceptions and knowledge of stroke among surviving patients with stroke and their carers. Age Ageing, 23, 293-298. http://dx.doi.org/10.1093/ageing/23.4.293. 